\title{
Colonización intraluminar testicular y diferenciación de la masa celular interna en ratones (Mus musculus)
}

\author{
Intraluminar testicular colonization and differentiation of the inner cell \\ mass in mice (Mus Musculus)
}

\author{
Láyonal Acosta*, Víctor Núñez, Jose Pino, Betty Shiga
}

Laboratorio de Reproducción y Biología del Desarrollo, Facultad de Ciencias Biológicas, Universidad Clencias Biológicas, Universidad Nacional Mayor de San Marcos Lima, Perú. Casilla 11-0058, Lima 11, Perú. Tel.: +51 $6197000-1529$ fax: $+516197000-1509$.

*Autor para las correspondencias, email Láyonal Acosta: acostaclg@gmail.com

\section{Resumen}

Cuando las células germinales primordiales (CGPs) son trasplantadas al testículo de otro individuo de la misma especie; colonizan el lumen de los túbulos seminíferos, buscando su nicho para diferenciarse en espermatozoides. Nuestro objetivo fue evaluar la colonización intraluminal de una suspensión de células de la masa celular interna $(\mathrm{MCl})$ obtenidas de blastocistos de ratones. Una suspensión de $\mathrm{MCl}$ obtenidos mediante una inmunocirugía en la red testicular de animales tratados previamente con ciclofosfamida para disminuir su propia espermatogénesis fueron trasladados a animales receptores. Se comprobó la presencia de minitúbulos intraluminales en 2 de 100 túbulos seminíferos, lo que demuestra que el trasplante de una suspensión de células de la masa celular interna pueden colonizar los túbulos seminíferos y además mantener una espermatogénesis xenogénica de manera sincrónica con el receptor.

Palabras Clave: Células madre pluripotentes, células madre germinales, testículo, minitúbulos, espermatogénesis.

\begin{abstract}
Primordial germ cells (PGC's) are transplanted to testicle of other individual of the same species, they colonize the lumen of the seminiferous tubules, seeking a niche to differentiate into sperm. Our objective was to evaluate the intraluminal colonization of a suspension of cells in the inner cell mass (IMC's) of blastocysts obtained from mice, using a novel technique. It was transplanted a suspension of ICM by mean of inmunosurgery into the rete testis of recipient animals which were previously treated with cyclophosphamide to reduce their own spermatogenesis. We confirmed the presence of intraluminal minitubules in 2 of 100 seminiferous tubules, demonstrating that transplantation of a suspension of cells from the inner cell mass can colonize the seminiferous tubules and also maintain a synchronously xenogenic spermatogenesis with the receiver.
\end{abstract}

Keywords: Pluripotent stem cells, germ stem cells, testes, minitubules, spermatogenesis.

\section{Introducción}

Durante el desarrollo temprano normal del embrión, sus blastómeros son totipotentes y por lo tanto capaces de generar un nuevo individuo por sí solas. Posteriormente, el desarrollo embrionario continúa y las células embrionarias empiezan a diferenciarse estableciendo su destino celular. En ratones, al séptimo día posterior a la copula, aproximadamente 100 células de la región del epiblasto se constituyen en las células germinales primordiales (PGCs), identificadas por su actividad fosfatasa alcalina (Chiquoine 1954). Las PGC's migran hacia las crestas gonadales, formando los gonocitos a los 11,5 días posterior a la copula (Loeffer \& Pottern 1997, McLaren 1998). Esta capacidad de las células germinales para participar en el proceso de desarrollo embrionario una y otra vez, indican que las CGPs son potencialmente inmortales (Donovan et al. 1997, Donovan 1998, Tsang et al. 2001).

La Terapia celular es una nueva herramienta para la medicina regenerativa, que hoy en día tiene su base en el uso de células madre. Una célula madre o stem cell se define como una célula progenitora, autorrenovable, capaz de regenerar uno o más tipos celulares diferenciados. Las células madres tienen la capacidad de llegar a convertirse en cualquiera de los más de 200 tipos de células diferentes del cuerpo y juegan un importante rol en reparar órganos y tejidos (Johnson \& Williams 2006).
Las células madre pluripotentes o embrionarias son las que derivan de la masa celular interna (MCI) de un embrión de mamífero en el estado de blastocisto, esto es dependiendo de la especie, $4-7$ días después de la fecundación y pueden ser expandidas sin límite in vitro (Evans \& Kaufman 1981, Martin 1981, Thomson et al. 1998).

Los gonocitos en los vertebrados pueden diferenciarse in vitro (Geijsen et al. 2004, Lacham-Kaplan et al. 2006, Nayernia et al. 2006); Asimismo, también se ha demostrado en el ratón que las células madres embrionarias (CME) pueden diferenciarse in vitro a células madres espermatogoniales (CME) con ayuda de un promotor y éstas son capaces de generar gametos haploides masculinos funcionales (Nayernia et al. 2007). Se ha podido demostrar que las células madres somáticas adultas pueden llegar a generar CMG, pero no tienen la capacidad de entrar a meiosis (Nayernia et al. 2007).

El transplante exitoso de células germinales, desde un individuo adulto a otro individuo adulto, fue descrito por primera vez en 1994 entre ratones inmunocompatibles (Brinster $\&$ Abarbock 1994, Brinster \& Zimmermann 1994). El transplante consistió en recolectar células germinales desde un animal donador e inyectarlas en los túbulos seminíferos del animal receptor, con el objetivo de que la espermatogénesis del animal donador se realice en los testículos del animal receptor. De esta manera al transplantar intraespecíficamente las células germinales, éstas 
colonizan la membrana basal de los túbulos seminíferos del animal receptor en busca del nicho donde se desarrollan las células madre. Se ha reportado que en transplantes de PGCs en ratas muestran una colonización atípica la cual se ha denominado como espermatogénesis intraluminal. Guzmán (2002) evaluó la colonización intraluminal de una suspensión cruda de PGC's de fetos de ratón de la cepa Balb $\mathrm{C}$ en los túbulos seminíferos de ratones adultos, obteniendo una colonización intraluminal en 1 de cada 100 túbulos seminíferos evaluados

El objetivo del presente estudio fue evaluar la colonización intraluminal de una suspensión de células de la masa celular interna (MCI) obtenidas de blastocistos de ratones.

\section{Material y métodos}

Animales.- Se utilizaron ratones de la cepa albina Swiss Rockefeller; machos $(\mathrm{N}=8)$ de 10 a 12 semanas de edad y de fertilidad comprobada y hembras vírgenes $(\mathrm{N}=8)$ de 6 a 8 semanas de edad. Los ratones machos receptores $(\mathrm{N}=8)$ fueron de la cepa C57BL (8 a 10 semanas). Ambas cepas se mantuvieron en condiciones de laboratorio (temperatura ambiental $22-24$ ${ }^{\circ} \mathrm{C}, 14 \mathrm{~h}$ luz: $10 \mathrm{~h}$ oscuridad), con acceso libre a una dieta con pellets (Purina, Perú) y agua ad libitum. Los protocolos siguieron los lineamientos del Consejo Nacional de Investigación para el cuidado y uso de animales de laboratorio (NRC 1996). Para la obtención de suero anti ratón se utilizó un conejo macho de la raza Nueva Zelanda y para la obtención del complemento, un cobayo macho de la raza criolla.

Químicos.- Ciclofosfamida (NEOPHOS), medio HTF suplementado con HEPES (LifeGlobal), solución Tyrode's

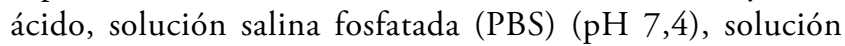
Tripsina-EDTA, Azul de Trypán, Ketamina, suero fisiológico, fijador Bouin.

Obtención de embriones preimplantacionales en el estadio de blastocisto.- Ratonas Swiss en etapa de estro o proestro, fueron cruzadas con un macho semental toda la noche y la presencia del tapón vaginal al día siguiente fue señal de que ocurrió la cópula y fue tomado como día 1 de la preńez. Las ratonas fueron posteriormente ( $96 \mathrm{~h}$ posterior a la copula) eutanizadas por dislocación cervical, se procedió a extraer los cuernos uterinos para la obtención de los embriones mediante un lavado con una solución de PBS ( $\mathrm{pH} 7,4)$.

Obtención de anticuerpos de conejo anti-bazo de ratón y complemento de cobayo. - Para la obtención de anticuerpos anti-ratón, se utilizó un conejo macho de la raza Nueva Zelanda al cual se le inyectó una concentración de $4 \times 10^{8}$ células $/ \mathrm{mL}$ del bazo de ratón, vía vena marginal de la oreja. Se recuperó 15 $\mathrm{mL}$ de sangre por sangría parcial, se colocó $3 \mathrm{~mL}$ en cada tubo Vacutainer de $15 \mathrm{~mL}$ con gel de sílica y se llevó a centrifugación a $2500 \mathrm{rpm}$. El suero obtenido fue colocado en tubos Eppendorf a volumen de $15 \mu \mathrm{L}$ y mantenido a $-20^{\circ} \mathrm{C}$ hasta su posterior uso. Antes de utilizar el suero, fue calentado en baño maría a $56^{\circ} \mathrm{C}$ por $30 \mathrm{~min}$. para su descomplementación y diluido 1:10. Para la obtención de complemento se utilizó un cobayo macho, al cual se le realizó una sangría total. La sangre obtenida fue colocada en tubos Vacutainer con gel de sílica y centrifugada a $2500 \mathrm{rpm}$. El suero obtenido fue colocado en tubos Eppendorf a volumen de $15 \mu \mathrm{L}$ y mantenidos a $-20^{\circ} \mathrm{C}$.

Inmunocirugía - La inmunocirugía de blastocistos de ratón fue realizada con algunas modificaciones al procedimiento de- sarrollado por Solter y Knowles (1975). La zona pelúcida fue removida utilizando la solución ácida de Tyrode's por $5 \mathrm{~min}$. luego los embriones fueron lavados por $3 \mathrm{~min}$., tres veces con PBS. Antes de la exposición del antisuero, los blastocistos fueron incubados a $37^{\circ} \mathrm{C}$ en medio HTF suplementado con HEPES (LifeGlobal) por $30 \mathrm{~min}$. Los blastocistos libres de zona pelúcida fueron expuestos a los anticuerpos de conejo anti-bazo de ratón diluido 1:10 por 30 min. y luego lavados tres veces con PBS, 5 min. cada uno. A continuación, los blastocistos fueron transferidos al complemento de cobayo (diluido a 1:10) con medio HTF suplementado con HEPES e incubado por 20 minutos a $37^{\circ} \mathrm{C}$. Seguidamente la MCI fue colocada en gotas de solución TripsinaEDTA e incubada por 5 minutos para permitir la disgregación de las células de la MCI. Las células de la MCI fueron lavadas tres veces con PBS y luego colocadas en medio HTF con HEPES y coloreadas con Azul de Trypán, con el objetivo de visualizar el ingreso de las células en el interior de los túbulos seminíferos. La suspensión de células a una concentración de $3 \times 10^{3}$ células por $\mathrm{mL}$ fue cargada en la pipeta de inyección.

Tratamiento con Ciclofosfamida (CP) y transplante de células madre pluripotentes.- La Ciclofosfamida (NEOPHOS), fue disuelta en solución salina $0,9 \%$ obteniendo una concentración final de $220 \mathrm{mg} / \mathrm{kg}$ [dosis equivalente a la dosis terapéutica en humanos $(750 \mathrm{mg} / \mathrm{kg})]$. Se utilizaron 8 ratones machos de la cepa $\mathrm{C} 57 \mathrm{BL}$ como receptores, a cada uno se les inyecto intraperitonealmente una dosis única de CP 4 días antes del transplante de las células madre. Para la realización de la microinyección, los ratones fueron anestesiados con $0,15 \mathrm{~mL}$ de Ketamina más $0,15 \mathrm{~mL}$ de suero fisiológico $(0,9 \%)$, una vez anestesiado el ratón se prosiguió a remover los testículos de la cavidad corporal para localizar la zona craneal del pedículo vascular donde llega el conducto eferente a la superficie del testículo. Cargada la pipeta de inyección con las células de la MCI y coloreadas con Azul de Trypán se inyectó directamente a la rete testis del testículo izquierdo del ratón, el testículo derecho fue usado como control al cual se le inyecto sólo medio HTF con HEPES más Azul de Trypán. Para la inyección en la rete testis, se utilizó una micropipeta de 50 a $80 \mu \mathrm{m}$ de diámetro la cual se insertó en un ángulo de $30^{\circ} \mathrm{y}$ una profundidad no mayor a $2 \mathrm{~mm}$. El llenado de los túbulos seminíferos siguió un camino al azar. La presión en la pipeta fue aplicada suavemente para evitar una ruptura interna de los límites de la rete testis. El volumen a inyectar en cada testículo fue de $50 \mu \mathrm{L}$. Al final del procedimiento, se cerró la abertura con hilos de sutura convencionales.

Análisis histológico.- Después de 35 días, los ratones fueron sacrificados por dislocación cervical, extrayéndoles los testículos y fijados con solución de Bouin por aproximadamente $16 \mathrm{~h}$, luego siguió la deshidratación y el parafinado de las muestras. Se procedió a obtener los cortes histológicos de $5 \mu \mathrm{m}$ de espesor con ayuda de un micrótomo rotativo Minot, los cuales fueron coloreados con hematoxilina y eosina $\mathrm{Y}$.

\section{Resultados}

Inmunocirugía.- Con la solución ácida de Tyrode's se destruyó exitosamente la zona pelúcida (Fig. 1), para luego enfrentar a la masa celular interna a los anticuerpos anti-ratón y complemento de cobayo (Fig. 2A) y finalmente mediante pipeteo suave obtener las células de la MCI disgregadas (Fig. 2B). 


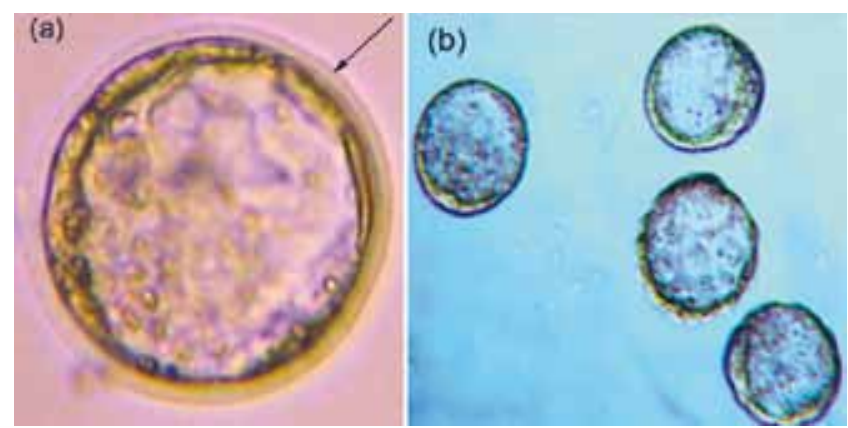

Figura 1. Blastocisto. A) Con zona pelúcida (Flecha) (250X). B) Sin zona pelúcida (100X).

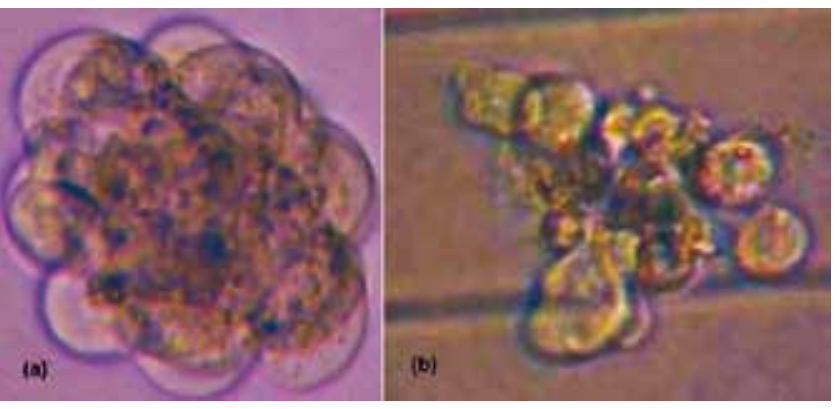

Figura 2. Masa celular interna sin zona pelúcida A) antes de exponerse a los anticuerpos anti-ratón; $B$. Después de exponerse a los anticuerpos anti-ratón. (250X).

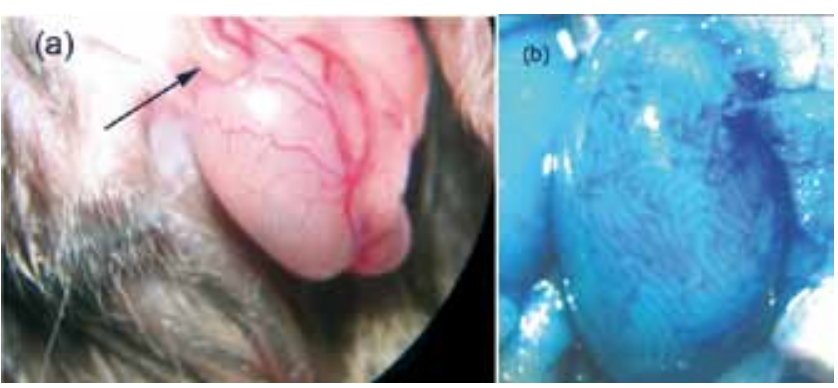

Figura 3. Testículos de ratón seleccionados para el transplante. A) Antes de la inoculación, mostrando el conducto eferente (Flecha) (15X); B) inoculación exitosa de la suspensión celular de la $\mathrm{MCl}$ mezclada con el colorante (20X).

Inyección a la rete testis.- Se inyecto exitosamente la suspensión de células disgregadas de la $\mathrm{MCI}$ a nivel de la rete testis (Fig. 3A), esto se evidencio por el patrón de coloración de los túbulos seminíferos con azul de Trypan (Fig. 3B).

Análisis del transplante de la MCI.- No se evidencio presencia de tumoración en los cortes histológicos evaluados. Se encontró que el $62,5 \%$ de los receptores evaluados presentaban colonización intraluminal, siendo esta colonización aleatoria en los túbulos seminíferos; en promedio se observó que sólo el 2\% de los túbulos seminíferos muestran minitúbulos (Figs. 4

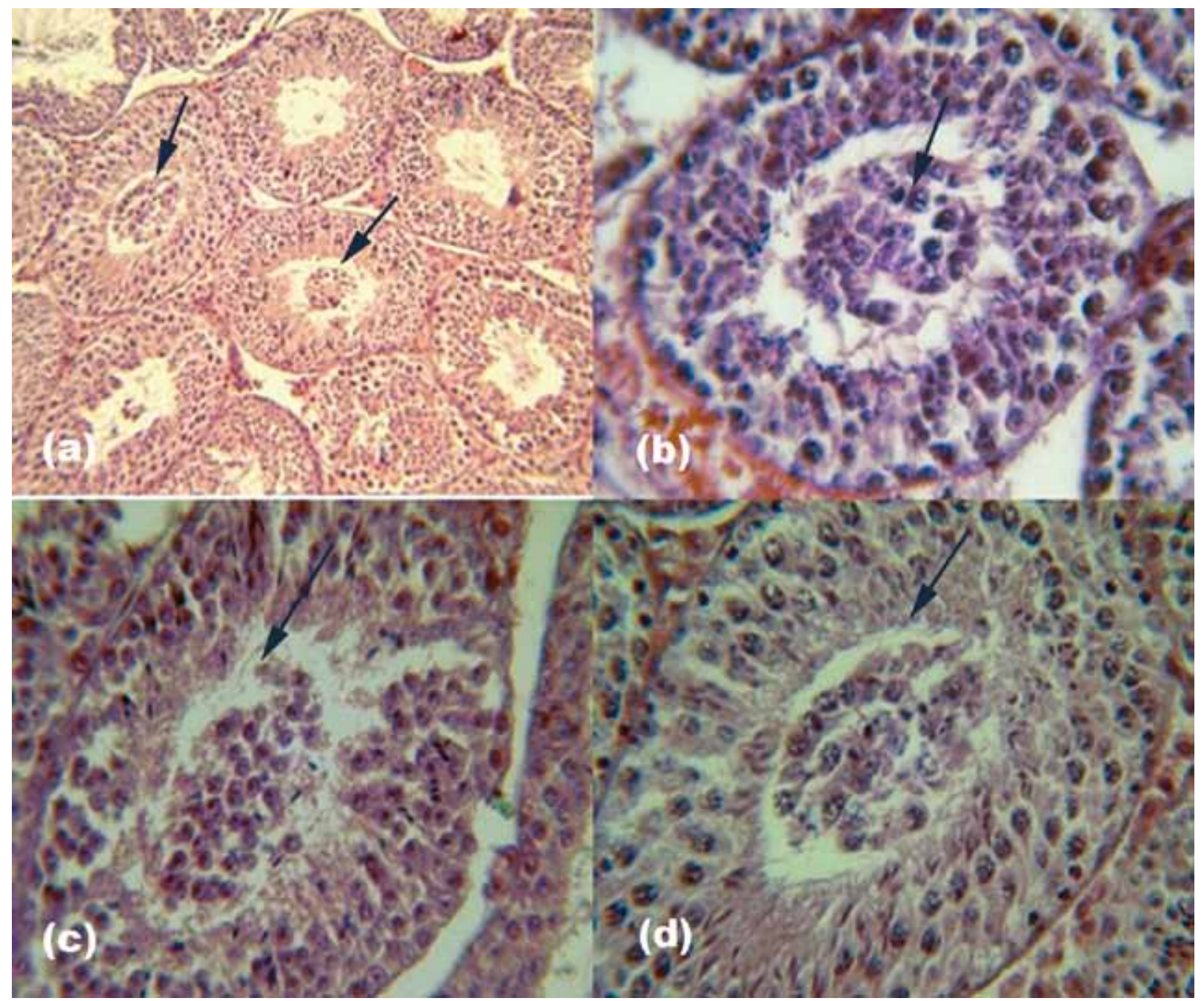

Figura 4. Colonización intraluminal y diferenciación de las células de la $\mathrm{MCl}$ y sincronización de los minitúbulos con respecto al epitelio seminífero con el receptor. Las flechas indican la formación de los minitúbulos en el lumen de los túbulos seminíferos del animal receptor $A$ (100X); B (400X); C (630X); D (630X). 


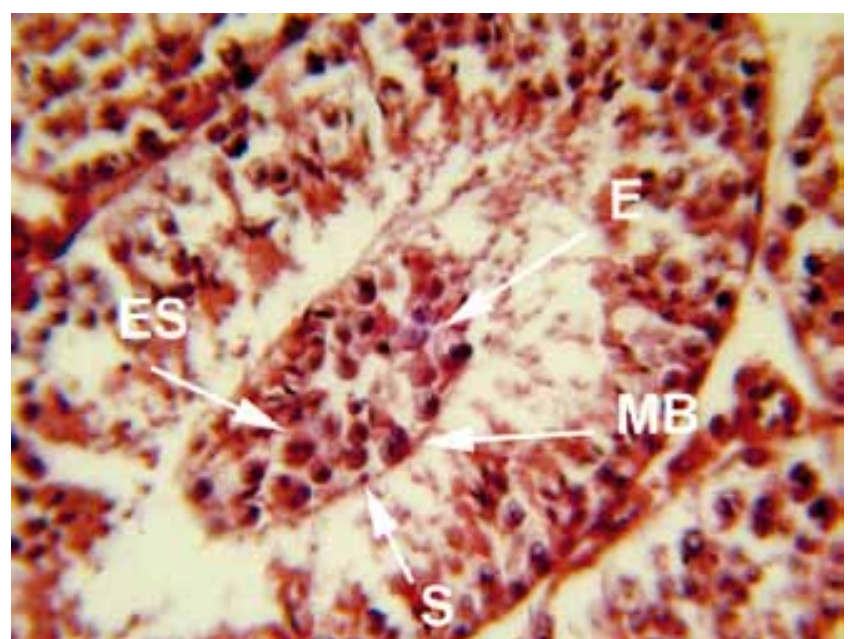

Figura 5. Colonización intraluminal y diferenciación de las células de la $\mathrm{MCl}$ (MB: estructura similar a membrana basal, S: célula de Sertoli, E: Espermatocito primario, ES: espermátide (630X).

A - D). Los minitúbulos formados en el lumen de los túbulos seminíferos muestran una sincronización de la espermatogénesis con respecto al epitelio seminífero del animal receptor (Fig. 4B, C y D; Fig. 5), Los testículos que solo fueron inyectados con medio HTF con HEPES más Azul de Trypán, no presentaron minitúbulos (Fig. 6).

\section{Discusión}

En el presente trabajo los resultados sugieren que las células de la MCI tienen la capacidad de diferenciarse in vivo a células de la línea germinal, presentándose en forma de minitúbulos.

Según Ogawa et al. (1997), de los diferentes procedimientos de inyección de células donadoras dentro de los túbulos seminíferos de un receptor, la técnica de inyección a nivel de rete testis ha demostrado ser un método sencillo, eficiente y reproducible. Utilizando esta técnica y células de la MCI, nosotros obtuvimos resultados en los que se observó la presencia de una colonización intraluminal en forma de minitúbulos con presencia de células espermatogénicas siendo estos resultados similares a los hallados por Jiang y Short (1995) en ratas y los de Guzmán (2005) en ratones, utilizando CGPs. Los minitúbulos sólo fueron obser- vados en los testículos que recibieron el transplante de células donadoras, más no en los testículos controles en los que sólo se les inyecto medio HTF con HEPES más el colorante vital, por tanto este nuevo epitelio seminífero hallado no sería un efecto ocasionado por el tratamiento previo con CP ni un artefacto producido por el procedimiento de la inyección, esto fue observado también por Jiang y Short (1995) y Guzmán (2005), quienes obtuvieron resultados congruentes a los nuestros utilizando el fármaco Busulfán en lugar de CP. La no presencia de tumoraciones (teratomas) discrepa con los resultados de Brinster y Avanbock (1994) quienes al inyectar células madre embrionarias de ratones a túbulos seminíferos de receptores estériles tuvieron como resultado la presencia de tumores.

La diferenciación obtenida in vivo de las células de la MCI, se debe a que éstas presentan un "estado de memoria" para su diferenciación, que se puede observar desde las etapas de divisiones tempranas cuando el primer blastómero dividido se encuentra destinado a formar predominantemente la estructura embrionaria, tal como lo demostró Piotrowska et al. (2001), además algunas de estas CMP están destinadas a ser parte de los túbulos seminíferos como células de Sertoli, es por ello que podemos encontrar a estas células dentro de los minitúbulos (Fig. 6).

Otra explicación seria que la ciclofosfamida eliminó todos los estadios espermatogenicos, con excepción de algunas células madre altamente resistentes como reportó Bucci y Meistrich (1987) utilizando Busulfan. Por otro lado, las CMP y las CGP comparten un gran número de marcadores moleculares similares y si se aplican estímulos apropiados puede diferenciarse de CMP a CGP in vitro, tal como explican Geijsen et al. (2004), Hubner et al. (2003) y Toyooka et al. (2003), e inclusive las CMP pueden llegar a formar gametos masculinos capaces de fecundar y desarrollar un individuo tal como lo demostró Nayernia et al. (2006) en ratones. Las células de Sertoli pueden sintetizar estímulos adecuados como el ácido retinoico (AR), tal como lo determino Cavazzini et al. (1996) en ratas, haciendo posible la activación del gen Stra8 para que pueda iniciarse la diferenciación de las CMP (Oulad-Abdelghani et al. 2006), bajo este mecanismo nuestras células transplantadas pueden diferenciarse en CGPs y estas a su vez en CMG in vivo.

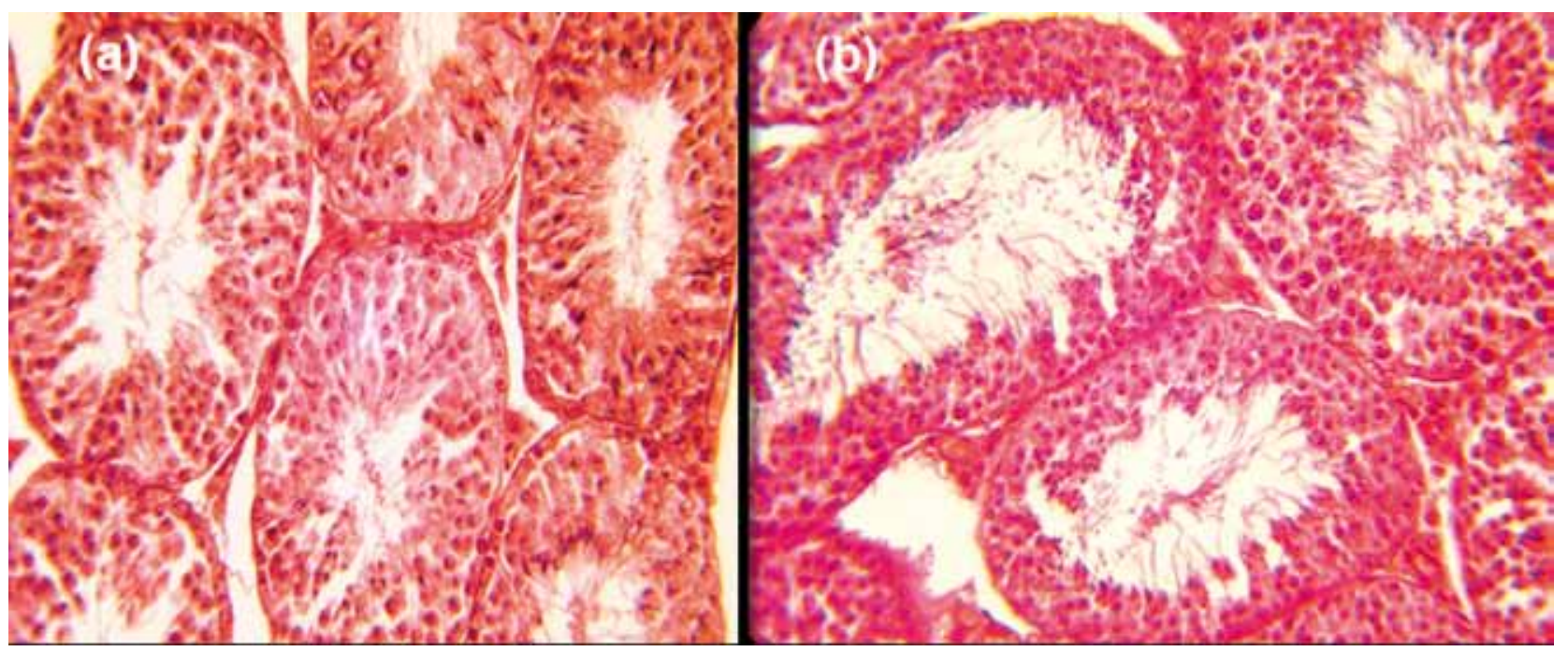

Figura 6. Testículo control. A) (250X) y B) (400X). 
Otro de los factores importantes y necesarios para que pueda desarrollarse la espermatogénesis es la existencia de una interacción entre las células de Sertoli y las CMG, la cual hace posible la activación de estas últimas para iniciar la espermatogénesis tal como lo comprobó Rossi et al. (1993) y Kanatsu-Shinohara et al. (2005) en ratones. En el presente trabajo, la presencia de minitúbulos nos sugiere que ha existido una diferenciación de la MCI, algunas de estas, a células de Sertoli y otras a CMG lo cual ha hecho posible un nicho con interacción, activación y desarrollo de una espermatogénesis intraluminal. Según Guzmán (2005), la colonización xenogénica del lumen de los túbulos seminíferos se debería a que la suspensión cruda de PGCs tienen además de las células ya mencionadas, células precursoras somáticas testiculares que al co-transplantarse formarían los minitúbulos en los túbulos seminíferos de los ratones receptores capaces de soportar proceso completo de espermatogénesis.

Los resultados muestran que el ciclo espermatogénico desarrollado en los minitúbulos a partir de la diferenciación de células de la MCI, se encuentra en sincronización con los túbulos hospederos, siendo este resultado concordante con lo obtenido por Jiang y Short (1995) y Guzmán (2005) que utilizaron en sus transplantes a las CGPs, es así que se puede sugerir que el microambiente tubular microambiente tubular se encuentra regulando tanto al epitelio seminífero tubular e intraluminal. Por otro lado no se ha observado la presencia de células de Leydig en asociación con el epitelio donador (minitúbulos), debido a que estas células no pueden sobrevivir en este microambiente Jiang y Short (1995).

Bajo las condiciones de la investigación, se encontró una frecuencia de $2 \%$ de desarrollo minitúbulos, por ratón receptor ya que las células donadoras presentan poca probabilidad de colonizar e interactuar, esto debido a que se ha utilizado una baja concentración de células, estos resultados son discordantes a los de Jiang y Short (1995) y Guzmán (2005) que encontraron 5 y $1 \%$ de minitúbulos, respectivamente en sus trabajos utilizando una concentración de células $10^{6}$ veces mayor.

Podemos señalar que la inyección de las células pluripotentes de la MCI ha demostrado ser una técnica adecuada para el estudio de la espermatogénesis en todos sus niveles demostrando que puede ser utilizada en las técnicas de reproducción asistida en humanos, para la recuperación del epitelio seminífero en varones que presentan una patología testicular y como un gran potencial en las terapias del futuro (McLaren 1998).

\section{Agradecimiento}

Al Consejo Superior de Investigación de la Universidad $\mathrm{Na}$ cional Mayor de San Marcos por el apoyo financiero (Estudio Fondo de Promoción de trabajo de Tesis de Pregrado, código 081001077).

\section{Literatura citada}

Brinster R.L. \& R.L. Avarbock. 1994. Germline transmission of donor haplotipe following spermatogonial transplation. Proceedings of the National Academy of Sciences. 91: $11303-7$

Brinster R.L. \& J.W. Zimmermann 1994. Spermatogenesis following male germ-cell transplantation. Proceedings of the National Academy of Sciences. 91: 11298-11302.
Bucci L.R. \& M.L. Meistrich. 1987. Effects of busulfan on murine spermatogenesis: cytotoxicity, sterility, sperm abnormalities, and dominant lethal mutations. Mutat Res.176:259-268.

Cavazzini D., M. Galdieri, S. Ottonello. 1996. Retinoic acid synthesis in the somatic cells of rat seminiferous tubules. Biochemical Biophysical Acta. 1313: 139-145.

Chiquoine A. 1954. The identification, origin, and migration of the primordial germ cells in the mouse embryo. Anatomical Record 118: 135 -146.

Donovan P., J. Resnick, L. Cheng, L. Lock. 1997. Towards the use of primordial germ cells for germline modification. In: Transgenic animal's generation and use, Ed Houdebine L.M. Harwood academic publishers

Donovan P. 1998. The germ cell: The mother of all stem cells. International Journal of Development Biology. 42: 1043-50.

Evans M. \& M. Kaufman 1981. Establishment in culture of pluripotential cells from Mouse embryos. Nature. 292: 154-6.

Geijsen N., M. Horoschak, K. Kim. 2004. Derivation of embryonic germ cells and male gametes from embryonic stem cells. Nature. 427: 148-154.

Guzmán L. 2005. Colonización intraluminal de los túbulos seminíferos de ratones post-transplante intraespecífico de células germinales primordiales. Tesis Profesional UNMSM, E.A.P Ciencias Biológicas, Lima.

Hubner K., G. Fuhrmann, L.K. Christenson. 2003. Derivation of oocytes from mouse embryonic stem cells. Science 300:1251-6.

Jiang F. \& R. Short. 1995. Male germ cell transplantation in rat: apparent synchronization of spermatogenesis between host and seminiferous epithelia. International Journal of Andrology. vol. 18: 326 - 330 .

Johnson A., E. Williams. 2006. Stem Cell Research., CRS Report for Congreso.

Kanatsu-Shinohara M., H. Miki, K. Inoue, et al. 2005. Germline niche transplantation restores fertility in infertile mice. Human Reproduction 9:2376-2380.

Lacham-Kaplan O, Chy H, Trounson A. 2006. Testicular cell conditioned medium supports differentiation of embryonic stem cells into ovarian structures containing oocytes. Stem Cells. vol. 24:266-273.

Loeffer M. \& C.S. Pottern. 1997. Stem cells and cellular pedigree conceptual introduction. In: CS Potten (Ed), Stem Cells. New York: Acad Press; p. 1-27.

Martin G. 1981. Isolation of a pluripotent cell line from early mouse embryos cultured in medium conditioned by teratocarcinoma stem cells. Proceeding of the National Academic of Science. USA. 78: 7634-7638.

McLaren A. 1998. Germ Cells and Germ Cell Transplantation. International Journal of Development Biology. 42: 855-860.

Nayernia K., J. Nolte, H.W. Michelmann, et al. 2006. In vitrodifferentiated embryonic stem cells give rise to male gametes that can generate offspring mice. Development Cell. vol. 11:125-132.

Nayernia K., L.J. Ho, W. Engel, et al. 2007. From stem cells to germ cells and from germ cells to stem cells. Iranian Journal of Reproductive Medicine 5(2):41-4.

NRC, National Research Council. 1996. Guide for the Care and Use of Laboratory Animals, 7th Edition. National Academy Press, Washington, DC.

Ogawa T., J. Aréchaga, M. Avarbock, R. Brinster. 1997. Transplantation of testis germinal cells into mouse seminiferous tubules. International Journal of Development Biology, vol.41:111- 122 . 
Oulad-Abdelghani M., P. Bouillet, D. Decimo, et al. 1996. Characterization of a premeiotic germ cell-specific cytoplasmic protein encoded by Stra8, a novel retinoic acid-responsive gene. Journal of Cellular Biology. vol. 135:469 - 477.

Piotrowska K, Wianny F, Pedersen RA, Zernicka-Goetz M. 2001. Blastomeres arising from the first cleavage division have distinguishable fates in normal mouse development. Development. vol.128: 3739-3748.

Rossi P., S. Dolci, C. Albanesi, P. Grimaldi, R. Ricca. 1993. Folliclestimulating hormone induction of steel factor (SLF) mRNA in mouse Sertoli cells and stimulation of DNA synthesis in spermatogonia by soluble SLF. Development Biology. vol. 155: 68-74.
Solter D. \& B. Knowles. 1975. Immunosurgery of mouse blastocyst. Proceeding of the National Academic Science USA., vol. 72: 5099-5102.

Thomson J., J. Itskovitz-Eldor, S. Shapiro, et al. 1998. Embryonic stem cell lines derived from human blastocysts. Science. vol. 282:1145-1147.

Toyooka Y., N. Tsunekawa, R. Akasu. 2003. Embryonic stem cells can form germ cells in vitro. PNAS 100:11457-11462.

Tsang T., P. Khoo, R. Jamieson, et al. 2001. The allocation and differentiation of mouse primordial germ cells. Int. Journal of Developmental Biology. vol. 45: 549-55. 